\title{
A new scale for the evaluation of clinical practice guidelines applicability: development and appraisal
}

\author{
Hui Li $i^{1,2,3^{*}} \mathbb{D}$, Runsheng Xie ${ }^{1,2,3}$, Yangyang Wang ${ }^{1,2,3}$, Xiuli Xie ${ }^{1,2,3}$, Jingwen Deng ${ }^{1,2,3}$ and Chuanjian Lu ${ }^{1,2,3}$
}

\begin{abstract}
Background: This study aimed to develop the clinical practice guidelines applicability evaluation (CPGAE-V1.0) scale and to evaluate its validity and reliability.

Methods: One hundred fifty assessors were invited to rate two rounds of importance scoring of the applicability indicators by using the 5-point Likert scale. Approved indicators formed the CPGAE-V1.0 scale, consisting of 19 items, arranged into 4 domains. We enrolled eligible clinicians from 8 institutions to evaluate 9 clinical practice guidelines using the CPGAE-V1.0 scale. Content validity, construct validity, internal reliability, intra-rater reliability, and responsiveness were analyzed.
\end{abstract}

Results: A total of 220 clinicians participated, and the response rate was 98.6\% (217/220). The CPGAE-V1.0 scale had favorable content validity. The four-factor model produced acceptable fit indices. The scale had an excellent internal consistency and item discrimination. It could identify the degree of applicability of the different dimensions between different guidelines. In all domains, 77.8\% (7/9) of CPGs in the minimum-scoring domain were concentrated in the "coordination of support" domain.

Conclusions: The CPGAE-V1.0 scale is a valid and reliable instrument for measuring the applicability of CPG.

Keywords: Applicability, Clinical practice guideline (CPG), Scale evaluation

\section{Background}

Clinical practice guidelines (CPGs) are playing an increasing role in the development of evidence-based health care, translating the best evidence into best practice principles [1]. Based on the specific clinical circumstances, CPGs can help practitioner and patient make decisions, thereby improving and ensuring medical quality [2, 3]. The aspects of CPG evaluation can be sorted into two parts: development and application. Currently, more than 20 kinds of tools have been adopted to assess and validate CPGs worldwide, and they are designed based on the developer's perspective [4]. Most of them are a scientific and comprehensive evaluation of CPGs,

\footnotetext{
* Correspondence: lihuitcm@126.com

${ }^{1}$ Department of Standardization of Chinese Medicine, The Second Affiliated Hospital of Guangzhou University of Chinese Medicine, Guangzhou, Guangdong, China

${ }^{2}$ Department of Standardization of Traditional Chinese Medicine, Guangdong Provincial Hospital of Chinese Medicine, Guangzhou, Guangdong, China Full list of author information is available at the end of the article
}

with a focus on the methodology, the collection of evidence, the reliability of the sources used in the development of the guidelines, etc. However, these tools lack pertinence in evaluating the applicability of CPGs, although these tools are involved in this area. For instance, in the AGREE, AGREE II, and Cluzeau instruments, only three to five items are about the applicability of the scale [5-7]. By using the AGREE instrument, a previous study has found several shortcomings in the applicability of the first batch of Chinese evidence-based CPGs in Traditional Chinese Medicine (TCM) [8]. The study showed that the average score for applicability (27.09\%) was the lowest of the six domains because these CPGs failed to sufficiently consider applicability in guideline development. Another study had a similar finding (i.e., the applicability domain not only had the lowest average score but also had the lowest intra-class correlation coefficient (ICC) value) and suggested that experts should

(c) The Author(s). 2018 Open Access This article is distributed under the terms of the Creative Commons Attribution 4.0 International License (http://creativecommons.org/licenses/by/4.0/), which permits unrestricted use, distribution, and reproduction in any medium, provided you give appropriate credit to the original author(s) and the source, provide a link to the Creative Commons license, and indicate if changes were made. The Creative Commons Public Domain Dedication waiver (http://creativecommons.org/publicdomain/zero/1.0/) applies to the data made available in this article, unless otherwise stated. 
focus on improving the applicability of guidelines in the future [9].

In fact, the applicability of a CPG is affected not only by its methodological quality but also by the external environment and conditions in which the CPG is used. For example, in a medical institution, it is necessary to consider whether it meets the requirements of the technology, equipment, staff, laws, and regulations when applying a guideline. From the user's perspective, applicability evaluation is more concerned with the applicability of CPGs to clinical practice, which obviously differs from their scientific evaluation. Therefore, we believe that the applicability evaluation should include a guideline's internal characteristics, its external environment, and the interrelationships between them.

With the growing number of CPGs, practitioners may be confused about whether the guideline is suitable according to their current situation. Thus, the present study aimed to develop the clinical practice guidelines applicability evaluation (CPGAE-V1.0) scale to help determine the applicability of CPGs and to evaluate its validity and reliability.

\section{Methods}

\section{Development of the CPGAE-V1.0 scale}

In the first phase, we formed a workgroup of experts in methodologies, hospital administrators, and clinicians. The workgroup members extensively consulted domestic and foreign literatures and related scales and then established 30 items. In addition, 15 self-made items were created after we invited 12 consultants (methodological experts, hospital managers, clinicians) for qualitative interviews. Finally, a total of 45 items were included. In the second phase, 150 assessors (methodological experts and clinicians) were invited to score each item using the 5point Likert scale vary from 1 ("least important") to 5 ("very important"). Based on the results of the importance score, approximately $60 \%$ of these items were further adjusted or deleted, and then the second-round scoring checklists for 19 items were sent to the same assessors.

\section{The CPGAE-V1.0 scale content and scoring method}

According to the second-round scoring results, the original CPGAE-V1.0 scale was developed, which consisted of 19 items across four domains:(1) technical level, 4 items; (2) coordination of support, 2 items; (3) structure and content, 9 items; (4) the role of the guideline, 4 items (Additional files 1 and 2). A four-point response scale was used to score each item of the CPGAE-V1.0 scale from 1 to 4 (very poor, poor, better, and very good). Supplementary explanations of each item were displayed in the scale to help understand the issues and concepts. The appraisers could list the reasons for their scores in the comment box detailed below each item. The standardized score of each domain (SDS) was calculated as follows [6]:

$$
\mathrm{SDS}=\frac{\text { Observed score-Minimum possible score }}{\text { Maximum possible score-Minimum possible score }} \times 100 \%
$$

In the above formula, observed score $=$ overall domain scores of all the appraisers; minimum possible score $=1$ (very poor) $\times$ No. of items within a domain $\times$ No. of appraisers; maximum possible score $=4$ (very good) $\times$ No. of items within a domain $\times$ No. of appraisers. The overall applicability score of the CPG was also computed in the same standardized method. Higher scores indicated better applicability of the CPG.

\section{CPGAE-V1.0 investigation}

In this phase, from November 2012 to February 2013, the applicability of nine CPGs was evaluated by eight TCM standard research and promotion base construction units, which were located in Guangzhou, Shanghai, Hangzhou, Nanjing, Shenzhen, Fujian, and Qingyuan. These CPGs were issued by the China Association of Chinese Medicine (CACM) in 2008, including menopausal syndrome (MS), chest stuffiness and pains (CSP), exogenous fever, colds, stroke, menstruation, chronic renal failure, transient ischemic attack, and eczema. MS and CSP were key diseases in this study. Eligible clinicians in each participating unit were invited to complete the CPGAE-V1.0 scale to evaluate one of the abovementioned CPGs. Specifically, the evaluator had to meet the following requirements: (1) the evaluator had the relevant professional knowledge involved in the evaluation guideline; (2) the evaluator was not the developer of the evaluation guideline; (3) the evaluator agreed to participate voluntarily in the study. The trained investigators issued and collected the questionnaire strictly in accordance with the survey manual. After we verified the data and filled out the quality control table, relevant documents were sent to the Guangdong Provincial Hospital of Chinese Medicine. The sample size of CPGAE-V1.0 investigation for each key disease was considered at least 50 , and for the other diseases, it was considered at least 10. In reality, the effective number of participants in the evaluation survey was 217 , and the ratio of sample size to items number was higher than 5:1. To evaluate the intra-rater reliability, one of the participating units had its evaluators re-scored 2 weeks later.

\section{Statistical analysis}

The demographic characteristics of the sample are described. The CPGAE-V1.0 scale was evaluated primarily by validity and reliability analysis. Validity analysis included content validity and construct validity. According to the expert importance score, the content validity index (CVI) was calculated to reflect the magnitude of 
the content validity, that is, the proportion of items on the 5-point Likert scale that achieved a rating of 3, 4 or 5 within all the assessors. Moreover, we used Bartlett's test of sphericity and the Kaiser-Meyer-Olkin (KMO) measure of sampling adequacy to examine the appropriateness of the sample size for conducting confirmatory factor analysis (CFA). A CFA model was constructed to analyze the construct validity of the CPGAE-V1.0 scale. The acceptable values of CFA model fit indices are shown in Table 1 [10-17]. Average variance extracted (AVE) was calculated as a test of discriminant validity. Reliability analysis included internal reliability and external reliability. The internal consistency of the total scale, the domains, and the score of the items were evaluated using Cronbach's alpha coefficient. The scale items were divided into two halves by the odd and even numbers of the items, and the consistency of these two parts' scores was calculated. The intra-class correlation coefficient (ICC) was used with a two-way random effects model to evaluate the size of the external reliability within each domain and overall score. Responsiveness analysis was intended to reflect the sensitivity of the scale for changes in the characteristics of different CPGs by calculating and comparing the various domains and overall score. We calculated the floor and ceiling effects as the percentage of the participants who had the minimum and maximum scores in each domain, for each item, and overall. Floor or ceiling effects were considered to be present when $\geq 15 \%$ of the respondents achieved the minimum or maximum possible score [18]. Missing data were dealt with in the following ways: (1) When more than $20 \%$ of items of the questionnaire were missing (that is, the number of missing items was $\geq 4$ ), it was considered invalid and was excluded; (2) when less than $20 \%$ of items of the questionnaire were missing (that is, the number of missing items was between 1 and 3 ), the missing

Table 1 Model fit indices summary

\begin{tabular}{|c|c|c|c|}
\hline Indices & $\begin{array}{l}\text { One-factor } \\
\text { model }\end{array}$ & $\begin{array}{l}\text { Four-factor } \\
\text { model }\end{array}$ & $\begin{array}{l}\text { Acceptable } \\
\text { values }\end{array}$ \\
\hline$\overline{x^{2}}$ & 583.34 & 325.88 & \\
\hline$p$ value & $<0.01$ & $<0.01$ & $>0.05[10]$ \\
\hline$x^{2} / d f$ (normed chi-square, NC) & 3.84 & 2.33 & $<3.00[11]$ \\
\hline $\begin{array}{l}\text { Root mean square error of } \\
\text { approximation (RMSEA) }\end{array}$ & 0.12 & 0.08 & $<0.08[12]$ \\
\hline Goodness of fit index (GFI) & 0.77 & 0.86 & $\geq 0.90[13]$ \\
\hline $\begin{array}{l}\text { Adjusted goodness of fit index } \\
\text { (AGFI) }\end{array}$ & 0.72 & 0.81 & $\geq 0.80[14]$ \\
\hline Normed fit index (NFI) & 0.81 & 0.90 & $\geq 0.90[13]$ \\
\hline Incremental fit index (IFI) & 0.86 & 0.94 & $\geq 0.90[15]$ \\
\hline Non-normed fit index (NNFI) & 0.84 & 0.92 & $\geq 0.90[16]$ \\
\hline Comparative fit index (CFI) & 0.85 & 0.94 & $\geq 0.90[17]$ \\
\hline
\end{tabular}

item's score was set as the average score of the answered items.

In this study, EpiData Version 3.1 (The EpiData Association, Odense, Denmark) was used to build the database and SPSS Version 17.0 (SPSS Inc., Chicago, IL, USA) software was used to process and analyze the data. The CFA model was constructed by $\mathrm{IBM}^{\circ} \mathrm{SPSS}^{\circ}$ Amos ${ }^{\mathrm{m}}$ 21.0 and confirmatory factor analysis was performed.

\section{Results}

\section{Characteristics of the sample}

A total of 220 clinicians were enrolled in the survey and all completed the survey scale within $20 \mathrm{~min}$. After eliminating three surveys with a proportion of missing items more than 20\%, the response rate was $98.6 \%(217 / 220)$. Among the 217 respondents, 96 (44.2\%) were chief physicians or associate chief physicians and 121 (55.8\%) were resident physicians or attending physicians. The median professional experience was 8 years (IQR 3-16 years).

\section{Validity study Content validity}

Results from the importance scoring by 150 experts showed that the CVI of each item and domain ranged from 0.89 to 0.99 and 0.94 to 0.99 , respectively, indicating that the appraisers found the CPGAE-V1.0 scale useful to evaluate CPG and the item and domain settings were satisfactory.

\section{Construct validity}

Bartlett's test indicated a strong correlation between variables and that we should reject the null hypothesis (chisquare $=3015.72, p<0.001$ ), which showed that factor analysis was appropriate. The KMO statistic of 0.94 (closed to 1.0) reflected that the sum of the correlations was large compared to the sum of the partial correlations, indicating a good fit for factor analysis and adequate sampling in the study.

A one-factor model was initially implemented, but most of the fit indices were below acceptable thresholds (Table 1). We constructed a four-factor model consisting of a total of 19 items across four domains from CPGAEV1.0 scale (Fig. 1). After adjusting the covariance relationship between the measurement indicators (items), the model produced acceptable fit indices as shown in Table 1 . The CFA results indicated that the best-fitting model was the four-factor solution. Specifically, the normed chi-square was lower than the threshold value of 3 , and the AFGI was 0.81 , which indicated adequate fit $[11,14]$. Furthermore, Fig. 2 and Table 2 show that there was valid evidence of CFA. No items had a factor loading $\leq 0.50$ or $\geq 0.95$, which conformed to the model recognition rules. Only two items had a factor loading $\leq$ 0.60 and communality $\leq 0.40$ : item 8 and item 14 . 


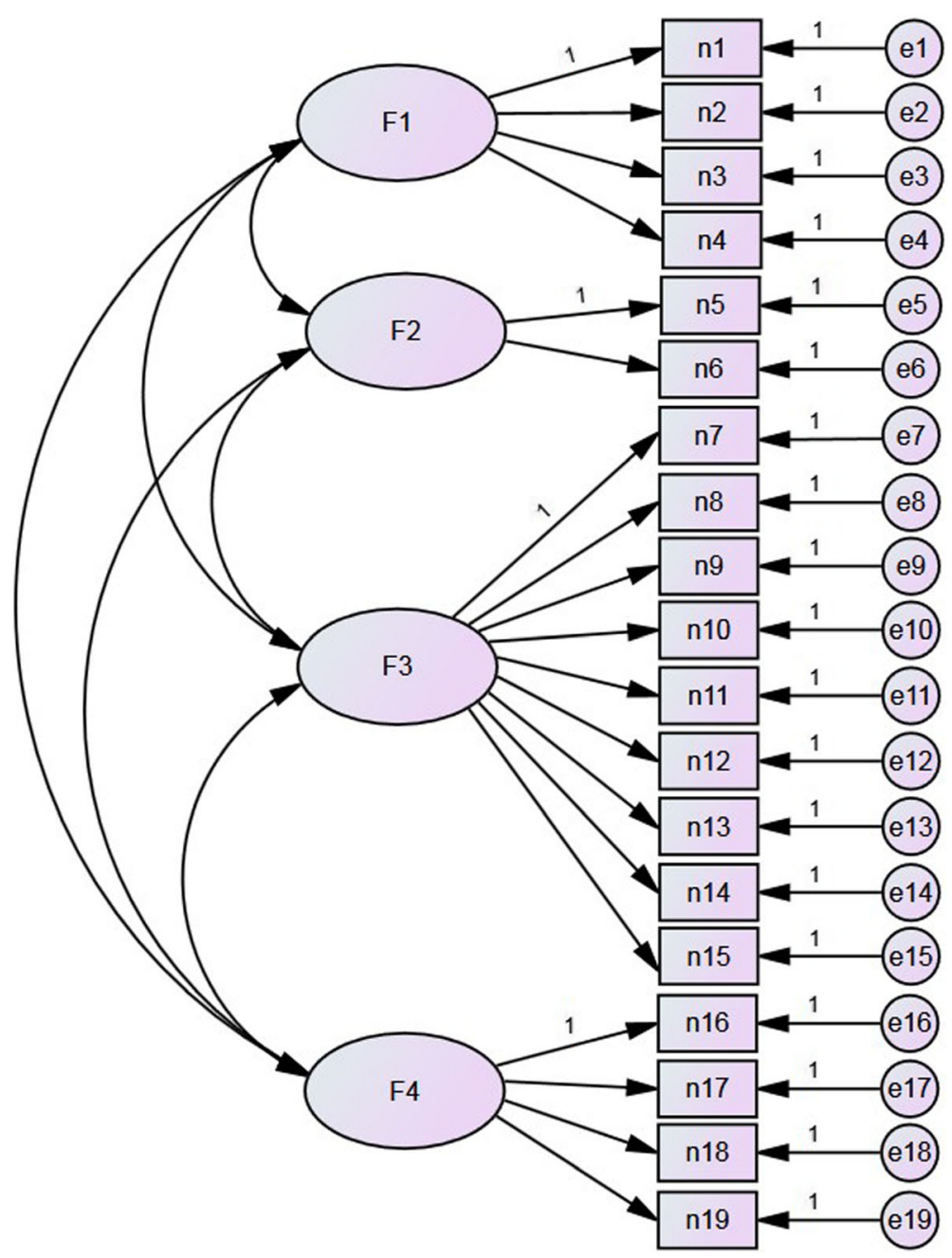

Fig. 1 The original proposed four-factor model of the CPGAE-V1.0 scale

\section{Discriminant validity}

As shown in Table 2, the AVE of F1, F2, F3, and F4 was $0.66,0.71,0.48$, and 0.63 , respectively. These results suggested that the items in the F3 domain could be further modified to improve the discriminant validity because the AVE of the F3 domain was lower than 0.50.

\section{Reliability study}

\section{Internal consistency}

For the CPGAE-V1.0 scale, Cronbach's alpha coefficient was higher than 0.90 and Guttman's split-half coefficient was 0.96 , demonstrating an almost perfect consistency (Table 3). The coefficient of each domain presented acceptable internal consistency (both greater than 0.80). After deleting the domains one by one, the overall reliability of the scale did not increase. Table 3 also shows the correlation between the four domains and the overall scale. With correlation coefficients ranging from 0.83 to 0.95 , the domains tended to highly positively correlate with the overall scale. The inter-correlations per domain ranged from 0.64 to 0.84 .

As shown in Table 4, the score of each item was positively correlated with the total score of the scale (the Spearman correlation coefficient ranged from 0.52 to 0 . $81)$. In addition to items $\mathrm{n} 8$ and $\mathrm{n} 14$, other item-to-score correlation coefficients were higher than 0.60. After removing the items one by one, overall Cronbach's alpha coefficients of the scale were $\leq 0.95$, indicating that the items had a good discrimination.

\section{Intra-rater (test-retest) reliability}

One of the participating units was selected and eight evaluators were re-scored 2 weeks later. The mean of the overall CPGAE-V1.0 scale standardized score was $81.80(\mathrm{SD}=8.17)$ in the first appraisal, and the mean of the score was $81.58(\mathrm{SD}=5.93)$ in the second time $(t=0$. 098, $p=0.925)$. The total ICC was $0.76(0.00$ to 0.95$)$, and the domains' ICCs ranged from 0.29 to 0.85 . 


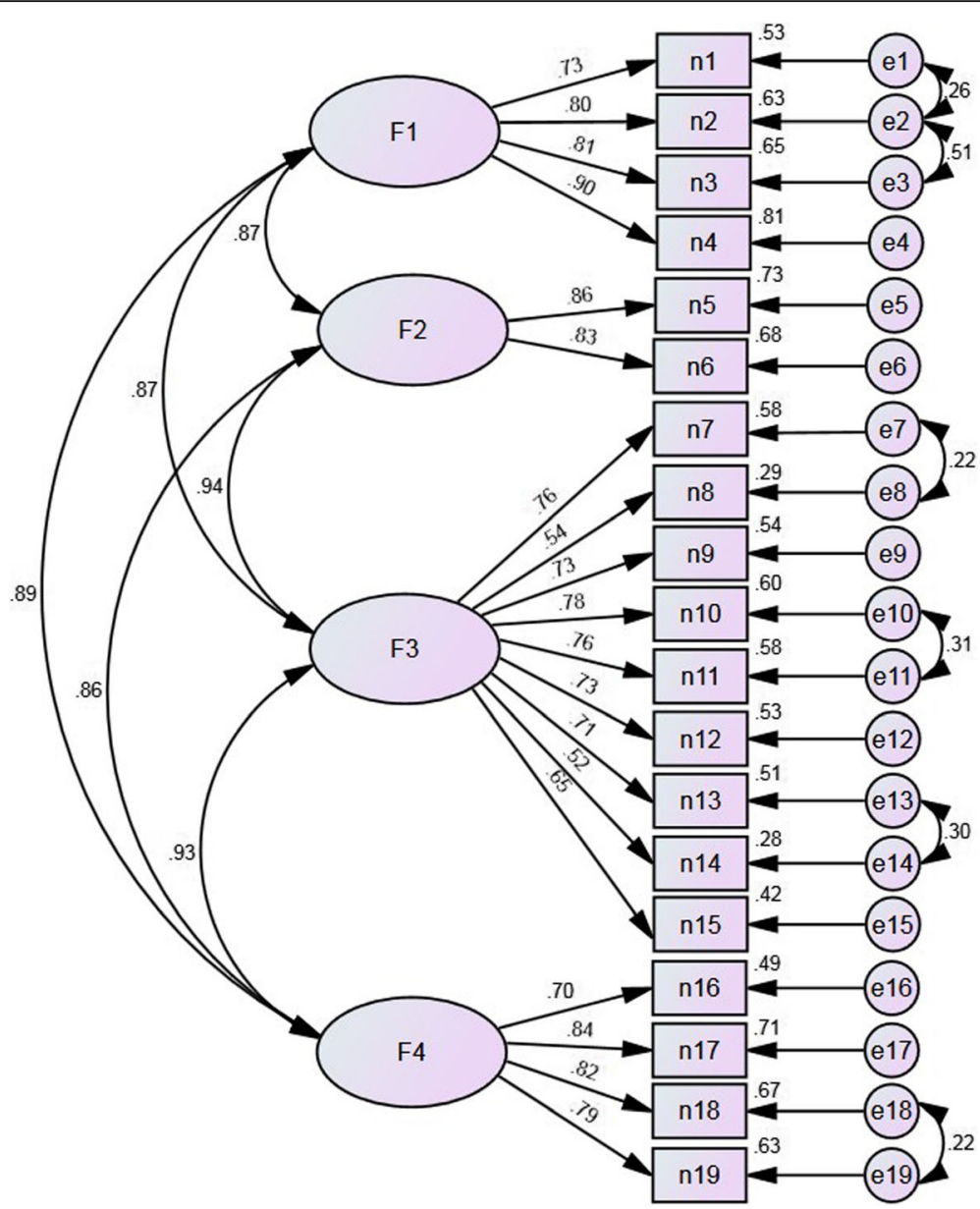

Fig. 2 Confirmatory factor analysis of the modified four-factor model of the CPGAE-V1.0 scale (standardized parameter estimates)

Weighted Cohen's kappa varied between -0.5 and 1.0 with 56.6\% (86/152) agreement (Additional file 3).

\section{Responsiveness analysis}

In the nine clinical practice guidelines published in 2008, the climacteric syndrome, menostaxis, and transient ischemic attack guideline was at a high applicability levels (close to 90 points), while chest stuffiness and pains had lower applicability (64.68 points). In all domains, the highest SDS of each CPG are not the same, 77.8\% (7/9) of CPGs of the minimum-scoring domain were concentrated in the "coordination of support" domain (Table 5).

\section{Floor and ceiling effect}

There were no floor effects in each domain, for each item, and overall. There were no ceiling effects in overall score $(9.7 \%)$. Form F1 to F4, the ceiling effects were 34 . $6,32.7,12.0$, and $23.5 \%$, respectively.

\section{Discussion}

The present paper describes a multi-staged development process, as well as a validity and reliability study of the
CPGAE-V1.0 scale. This is a reliable and effective assessment tool designed to provide a framework for measuring the applicability of clinical practice guidelines to help users understand the inadequacies of the guidelines and make choices.

The factor analysis results confirmed our conceptual framework of applicability, lending support to the assumption that the applicability of clinical guidelines is composed of four distinct domains, each domain assessed by its key items. Benefitting from the importance scoring of 150 assessors in two rounds, the valuable and approbatory items and domains were screened out. Furthermore, the measurement variables in CFA could be interpreted to a higher degree because each item exhibited sufficient factor loading (both greater than 0.50). However, the F3 domain (structure and content) indicated that slightly weaker discriminant validity may be weakened by the lower AVE. Within the F3 domain, the item-to-total score correlation coefficient of $\mathrm{n} 8$ and $\mathrm{n} 14$ were lower than other items, and the communality of items $\mathrm{n} 8$ and $\mathrm{n} 14$ were lower than the suggested minimum of 0.40 . To improve the explanatory power of the 
Table 2 Validity evidence

\begin{tabular}{|c|c|c|c|c|}
\hline Domain and items & Factor loading & Communality & Measurement error & Average variance extracted \\
\hline \multicolumn{4}{|l|}{ F1 Technical level } & 0.66 \\
\hline $\mathrm{n} 1$ & 0.73 & 0.53 & 0.47 & \\
\hline n2 & 0.80 & 0.64 & 0.36 & \\
\hline n3 & 0.81 & 0.65 & 0.35 & \\
\hline n4 & 0.90 & 0.81 & 0.19 & \\
\hline \multicolumn{4}{|c|}{ F2 Coordination of support } & 0.71 \\
\hline n5 & 0.86 & 0.74 & 0.26 & \\
\hline n6 & 0.83 & 0.68 & 0.32 & \\
\hline \multicolumn{4}{|c|}{ F3 Structure and content } & 0.48 \\
\hline $\mathrm{n} 7$ & 0.76 & 0.58 & 0.42 & \\
\hline $\mathrm{n} 8$ & 0.54 & 0.29 & 0.71 & \\
\hline n9 & 0.73 & 0.54 & 0.46 & \\
\hline $\mathrm{n} 10$ & 0.78 & 0.60 & 0.40 & \\
\hline $\mathrm{n} 11$ & 0.76 & 0.58 & 0.42 & \\
\hline $\mathrm{n} 12$ & 0.73 & 0.53 & 0.47 & \\
\hline $\mathrm{n} 13$ & 0.71 & 0.51 & 0.49 & \\
\hline $\mathrm{n} 14$ & 0.53 & 0.28 & 0.72 & \\
\hline $\mathrm{n} 15$ & 0.65 & 0.42 & 0.58 & \\
\hline \multicolumn{4}{|c|}{ F4 The role of the guideline } & 0.63 \\
\hline n16 & 0.70 & 0.49 & 0.51 & \\
\hline $\mathrm{n} 17$ & 0.84 & 0.71 & 0.29 & \\
\hline $\mathrm{n} 18$ & 0.82 & 0.67 & 0.33 & \\
\hline n19 & 0.80 & 0.63 & 0.37 & \\
\hline
\end{tabular}

F3 domain, its items could be further modified, especially items $\mathrm{n} 7$ and $\mathrm{n} 8$. Although the four-factor model had favorable construct validity, we do not know the relative contribution of each domain to the overall applicability of a guideline. A similar situation exists in other assessment instruments, and we need to explore solutions in the future [6].

Our reliability analysis results demonstrated that the CPGAE-V1.0 scale had an excellent internal consistency and item discrimination. In general, all the domains and the total score reached the recommended minimum of 0.70 for Cronbach's alpha coefficient, meaning they should be considered acceptable [18]. As shown in Table 3, Cronbach's alpha coefficient of the CPGAE-V1.0 scale was satisfactory $(\geq 0.95)$. These items were correlated with the measurement purpose of the scale, and the overall reliability of the scale did not increase if any item was excluded. However, poor intra-rater reliability was found, and the possible reasons are follows. First, poor retest reliability is related to the setting of the range and pre-evaluation training. On rechecking the original record, more than $95 \%$ of raters scored each item as "better" or "very good", which were in the same direction but different classification. This reflected that the grading of the scale was not clear enough and pre-evaluation training did not fully clarify the distinction between levels. Second, an

Table 3 Domain-to-total score correlations (Spearman rank) and the inter-correlations per domain

\begin{tabular}{|c|c|c|c|c|c|c|c|c|}
\hline Domains & Items & $r_{\mathrm{s}}$ & Cronbach's alpha & Cronbach's alpha (if domain deleted) & $r_{F 1}$ & $r_{\mathrm{F} 2}$ & $r_{F 3}$ & $r_{\mathrm{F} 4}$ \\
\hline F1 Technical level & 4 & $0.85^{*}$ & 0.90 & 0.94 & 1.00 & & & \\
\hline F2 Coordination of support & 2 & $0.83^{*}$ & 0.82 & 0.95 & $0.64^{*}$ & 1.00 & & \\
\hline F3 Structure and content & 9 & $0.95^{*}$ & 0.89 & 0.94 & $0.72^{*}$ & $0.76^{*}$ & 1.00 & \\
\hline F4 The role of the guideline & 4 & $0.93^{*}$ & 0.87 & 0.94 & $0.74^{*}$ & $0.75^{*}$ & $0.84^{*}$ & 1.00 \\
\hline Total scale & 19 & 1.00 & 0.95 & - & & & & \\
\hline
\end{tabular}


Table 4 Item-to-total score correlations (Spearman rank) for the CPGAE-V1.0 scale

\begin{tabular}{|c|c|c|c|}
\hline Item & $r_{s}^{*}$ & Corrected $r_{\mathrm{s}}^{*}$ & Cronbach's alpha (if item deleted) \\
\hline n1 & 0.71 & 0.72 & 0.95 \\
\hline $\mathrm{n} 2$ & 0.76 & 0.75 & 0.95 \\
\hline n3 & 0.74 & 0.72 & 0.95 \\
\hline $\mathrm{n} 4$ & 0.81 & 0.80 & 0.95 \\
\hline n5 & 0.78 & 0.78 & 0.95 \\
\hline n6 & 0.75 & 0.75 & 0.95 \\
\hline n7 & 0.70 & 0.74 & 0.95 \\
\hline n8 & 0.52 & 0.53 & 0.95 \\
\hline n9 & 0.68 & 0.69 & 0.95 \\
\hline n10 & 0.72 & 0.74 & 0.95 \\
\hline $\mathrm{n} 11$ & 0.74 & 0.74 & 0.95 \\
\hline $\mathrm{n} 12$ & 0.72 & 0.71 & 0.95 \\
\hline n13 & 0.71 & 0.70 & 0.95 \\
\hline n14 & 0.58 & 0.52 & 0.95 \\
\hline n15 & 0.67 & 0.62 & 0.95 \\
\hline $\mathrm{n} 16$ & 0.68 & 0.66 & 0.95 \\
\hline $\mathrm{n} 17$ & 0.80 & 0.78 & 0.95 \\
\hline $\mathrm{n} 18$ & 0.79 & 0.77 & 0.95 \\
\hline n19 & 0.79 & 0.76 & 0.95 \\
\hline
\end{tabular}

${ }^{*} P<0.001$

insufficient retest sample size resulted in increased sampling error and weakened the reliability and stability.

Previous studies have found several shortcomings in the applicability of CPGs of Traditional Chinese Medicine and suggest that we should pay special attention to improve this area in the future $[8,9]$. At the time of this study, nine TCM clinical practice guidelines had been released for almost 5 years. Our evaluation results indicate that the applicability of some guidelines is still high (i.e., the CS and TIA guidelines, which earned close to
90 points), while the individual guidelines are relatively low (i.e., CSP, 64.68 points). These data suggest that developers should consider revising the guidelines to improve the level of applicability. In all domains, most CPGs $(77.8 \%)$ in the minimum-scoring domain were concentrated in the "coordination of support" domain. According to the composition of the domain, the data indicate that these guidelines lack coordination to the other relevant standards or guidelines in interrelated content. Meanwhile, the relevant medical resources (such as medical technology and operating room), which should be supported in the implementation, are insufficient. Previous studies suggested users evaluate the quality of CPGs before adopting them [6]. However, some authors have shown that the methodological quality of CPGs may not necessarily equal the validity of recommendations, which confuses practitioners when deciding on the appropriate guideline $[19,20]$. From a practitioner's perspective, they are more concerned with whether the guideline is applicable for clinical practice in the situation they are facing. Under these circumstances, we recommend using the CPGAE-V1.0 scale in helping to understand the applicability of CPGs before adopting them. In this way, they can assess the applicability of CPGs to clinical practice through the applicability evaluation.

Taking into account the feasibility of the practical application, each item of the CPGAE-V1.0 scale listed relevant supplementary explanation for the appraisers to understand the issues and concepts involved in the item. As completing the scale does not involve any complex calculations, the effective response rate of participation was relatively high. However, there are some limitations in the current study. First, participation in this study was limited to clinicians who played a major role in the medical decision-making process, but we did not survey other medical staff who also participate in medical decision-making, such as nurses. Second, a 4-point

Table 5 The CPGAE-V1.0 domain scores of nine CPGs

\begin{tabular}{lllllll}
\hline CPG & $N$ & F1 & F2 & F3 & F4 & Overall applicability score \\
& & Technical level & Coordination of support & Structure and content & The role of the guideline & \\
\hline CS & 62 & 89.38 & 85.48 & 88.77 & 87.63 & 88.31 \\
CSP & 57 & 66.23 & 51.46 & 66.44 & 65.79 & 64.68 \\
EF & 11 & 77.88 & 83.33 & 79.12 & 72.73 & 77.96 \\
CC & 12 & 76.39 & 75.00 & 81.17 & 73.61 & 77.92 \\
Ap & 24 & 76.04 & 73.61 & 81.48 & 75.69 & 78.29 \\
Me & 10 & 90.83 & 85.00 & 91.11 & 87.50 & 89.65 \\
CRF & 16 & 72.40 & 66.67 & 71.56 & 67.71 & 70.41 \\
TIA & 10 & 89.17 & 86.67 & 89.26 & 91.67 & 89.47 \\
EC & 15 & 78.52 & 74.44 & 75.80 & 78.33 & 76.76 \\
\hline
\end{tabular}

Abbreviations: CS climacteric syndrome, CSP chest stuffiness and pains, EF exogenous fever, CC common cold, Ap apoplexy, Me menostaxis, CRF chronic renal failure, TIA transient ischemic attack, Ec eczema 
response scale was used to score each item of the CPGAE-V1.0 scale, referring to the AGREE instrument, while some studies considered that a 7-point response scale may have been more in compliance with methodological requirements and instrument reliability [7, 21]. However, a 7-point response scale may be more difficult and take more time to finish [22]. Finally, the low sample size of intra-rater reliability is another disadvantage. According to the COSMIN checklist, this small sample size $(<30)$ included in the intra-rater reliability analysis is poor [23]. An inadequate sample size will weaken the reliability and stability of the retest results (i.e., lower kappa values). When other researchers use this tool in the future, they could refer to the COSMIN checklist and involve more than 100 raters in the retest to improve the reliability of the results. This is also the focus of our next version. We grant that the development of this first version of a clinical practice guidelines applicability evaluation scale was not perfect, but we hoped that this report will inspire other researchers in this field to conduct similar studies.

\section{Conclusions}

The applicability evaluation of clinical practice guidelines is a creative and challenging endeavor. Our findings indicate that the CPGAE-V1.0 scale is a valid and reliable instrument for measuring the applicability of CPGs. This scale can be used conveniently to evaluate the applicability of CPGs in practical applications and to find their deficiencies to promote the application and improvement of CPGs.

\section{Additional files}

Additional file 1: CPGAE-V1.0 scale (Chinese version). (PDF $360 \mathrm{~kb}$ )

Additional file 2: CPGAE-V1.0 scale (English version). (PDF $156 \mathrm{~kb}$ )

Additional file 3: Table S1. Weighted Cohen's kappa of each item. (DOCX $32 \mathrm{~kb})$

\section{Abbreviations \\ AGFI: Adjusted goodness of fit index; Ap: Apoplexy; AVE: Average variance extracted; CACM: China Association of Chinese Medicine; CC: Common cold; CFA: Confirmatory factor analysis; CFI: Comparative fit index; CPG: Clinical practice guideline; CPGAE-V1.0: Clinical practice guidelines applicability evaluation; CRF: Chronic renal failure; CS: Climacteric syndrome; CSP: Chest stuffiness and pains; CVI: Content validity index; Ec: Eczema; EF: Exogenous fever; GFI: Goodness of fit index; ICC: Intra-class correlation coefficient; IFI: Incremental fit index; KMO: Kaiser-Meyer-Olkin; Me: Menostaxis; MS: Menopausal syndrome; NC: Normed chi-square; NFI: Normed fit index; NNFI: Non-normed fit index; RMSEA: Root mean square error of approximation; SDS: The standardized score of each domain; TCM: Traditional Chinese Medicine; TIA: Transient ischemic attack}

\section{Acknowledgements}

The authors especially thank the 12 consultants $(X L, B D, Y H, X Y, H W, H Y, X Z$, $Z P, A C, H X, S P$, and ZW) for their qualitative interviews. They are thankful to the eight TCM standards research and promotion base construction units and their clinicians for participating in the study.

\section{Funding}

This research has received funding from the Special Research Fund for Traditional Chinese Medicine Science and Technology of Guangdong Provincial Hospital of Chinese Medicine (YN2015MS22).

\section{Availability of data and materials}

The datasets generated and/or analyzed during the current study are not publicly available because our institution has relevant regulations, but they are available from the corresponding author on reasonable request.

\section{Authors' contributions}

$H L$ conceived and designed the study. HL and RX analyzed the data. HL, RX, and YW drafted the manuscript. YW and XX sorted out the relevant materials. XX and JD collected the survey data. $\mathrm{HL}$ and $\mathrm{CL}$ guided the implementation of the study. All authors read and approved the final manuscript.

\section{Ethics approval and consent to participate}

This study has received approval from the Institutional Ethics Committee of Guangdong Provincial Hospital of Traditional Chinese Medicine (Ethical review approval number: B2013-016-01).

\section{Competing interests}

The authors declare that they have no competing interests.

\section{Publisher's Note}

Springer Nature remains neutral with regard to jurisdictional claims in published maps and institutional affiliations.

\section{Author details}

'Department of Standardization of Chinese Medicine, The Second Affiliated Hospital of Guangzhou University of Chinese Medicine, Guangzhou, Guangdong, China. ${ }^{2}$ Department of Standardization of Traditional Chinese Medicine, Guangdong Provincial Hospital of Chinese Medicine, Guangzhou, Guangdong, China. ${ }^{3}$ Engineering and Technology Research Center of Standardization of Traditional Chinese Medicine, Guangzhou, Guangdong, China.

Received: 22 July 2017 Accepted: 6 April 2018 Published online: 25 April 2018

\section{References}

1. Brietzke SE. Individualized clinical practice guidelines: the next step in the evidence-based health care evolution? Otolaryngol Head Neck Surg. 2014; 150(3):342-5.

2. Field MJ, Lohr KN, Committee to advise the public health service on clinical practice guidelines, Institute of Medicine. Clinical practice guidelines: directions for a new program. Washington, DC: National Academy Press; 1990.

3. Woolf SH, Grol R, Hutchinson A, Eccles M, Grimshaw J. Clinical guidelines: potential benefits, limitations, and harms of clinical guidelines. BMJ. 1999; 318:527-30.

4. Vlayen J, Aertgeerts B, Hannes K, Sermeus W, Ramaekers D. A systematic review of appraisal tools for clinical practice guidelines: multiple similarities and one common deficit. Int J Qual Health Care. 2005;17(3):235-42.

5. Cluzeau FA, Littlejohns P, Grimshaw JM, Feder G, Moran SE. Development and application of a generic methodology to assess the quality of clinical guidelines. Int J Qual Health Care. 1999;11(1):21-8.

6. The AGREE Collaboration. Development and validation of an international appraisal instrument for assessing the quality of clinical practice guidelines: the AGREE project. Qual Saf Health Care. 2003;12(1):18-23.

7. Brouwers MC, Kho ME, Browman GP, Burgers JS, Cluzeau F, Feder G, Fervers B, Graham ID, Grimshaw J, Hanna SE, et al. AGREE II: advancing guideline development, reporting and evaluation in health care. CMAJ. 2010;182(18): E839-42.

8. Yu WY, Xu JL, Shi NN, Wang LY, Han XJ, Wang YY, Lv AP. Assessing the quality of the first batch of evidence-based clinical practice guidelines in traditional Chinese medicine. J Tradit Chin Med. 2011;31(4):376-81.

9. Choi TY, Choi J, Lee JA, Jun JH, Park B, Lee MS. The quality of clinical practice guidelines in traditional medicine in Korea: appraisal using the AGREE II instrument. Implement Sci. 2015;10:104. 
10. Hoyle RH. Structural equation modeling: concepts, issues, and applications. In: Hoyle RH, editor. The structural equation modeling approach: basic concepts and fundamental issues. Thousand Oaks: Sage Publications; 1995.

11. Kline RB. Principles and practice of structural equation modeling (2nd ed.). New York: The Guilford Press; 2005.

12. McDonald RP, Ho MH. Principles and practice in reporting structural equation analyses. Psychol Methods. 2002;7(1):64-82.

13. Hair JF, Tatham RL, Anderson RE, Black W. Multivariate data analysis (6th ed. ). Upper Saddle River: Pearson Prentice Hall; 2006.

14. Marsh HW, Balla JR, McDonald RP. Goodness-of-fit indexes in confirmatory factor analysis: the effect of sample size. Psychol Bull. 1988;103(3):391-410.

15. Bollen KA. Structural equations with latent variables. New York: Wiley; 1989.

16. Bentler PM, Bonett DG. Significance tests and goodness-of-fit in the analysis of covariance structures. Psychol Bull. 1980;88(3):588-606.

17. Bentler PM. Comparative fit indexes in structural models. Psychol Bull. 1990; 107(2):238-46.

18. McHorney CA, Tarlov AR. Individual-patient monitoring in clinical practice: are available health status surveys adequate? Qual of life res. 1995;4(4):293-307.

19. Burgers JS, Bailey JV, Klazinga NS, Van Der Bij AK, Grol R, Feder G. Inside guidelines: comparative analysis of recommendations and evidence in diabetes guidelines from 13 countries. Diabetes Care. 2002;25(11):1933-9.

20. Watine J, Friedberg B, Nagy E, Onody R, Oosterhuis W, Bunting PS, Charet $J C$, Horvath AR. Conflict between guideline methodologic quality and recommendation validity: a potential problem for practitioners. Clin Chem. 2006;52(1):65-72.

21. Streiner DL, Norman GR. Health measurement scales: a practical guide to their development and use (4th ed.). Oxford: Oxford University Press; 2008.

22. Tøndering J, Jensen C. Perceived prominence and scale types. In: Eriksson A, Lindh J, editors. Proceedings Fonetik 2005: the XVIIIth Swedish phonetics conference. Göteborg; 2005.

23. Mokkink LB, Terwee CB, Patrick DL, Alonso J, Stratford PW, Knol DL, Bouter LM, de Vet HC. The COSMIN checklist for assessing the methodological quality of studies on measurement properties of health status measurement instruments: an international Delphi study. Qual Life Res. 2010;19(4):539-49.

Ready to submit your research? Choose BMC and benefit from:

- fast, convenient online submission

- thorough peer review by experienced researchers in your field

- rapid publication on acceptance

- support for research data, including large and complex data types

- gold Open Access which fosters wider collaboration and increased citations

- maximum visibility for your research: over $100 \mathrm{M}$ website views per year 